\title{
Effect of Lamotrigine on Ouabain-Induced Arrhythmia in Isolated Atria of Guinea Pigs
}

\author{
Marjan Mirsalehi ${ }^{1}$, Golrokh Malihi $^{2}$, Eshagh Bahrami $^{3}$, Zeinab Akbarnejad $^{1}$, Sayedali Ahmadi ${ }^{3 *}$ (1) \\ Received: 18 Jun 2020 \\ Published: 20 Oct 2021
}

\begin{abstract}
Background: Lamotrigine (LTG) is an antiepileptic drug used in the treatment of seizures, mood disorders, and cognitive problems. The cardiac effects of LTG, such as LTG toxicity and SUEDP, have been studied. This is an in vitro study examining the effect of LTG on isolated atria of guinea pigs.

Methods: The atria of 21 male Guinea pigs were isolated and stabilized in Krebs-solution and physiologic condition. The rhythm of contraction, contractile force, and heart rate were recorded. In 7 atria, LTG at the doses of 2, 4, 8, and $16 \mathrm{mg} / \mathrm{mL}$ were added and the contractile forces and heart rates were recorded and compared together. In the next step, in 14 atria, 8 were pretreated with LTG, and 6 without pretreatment were exposed to ouabain, and the times of the onset of effect, arrhythmia, and asystole were recorded. The statistical comparisons were made by using Student's t test and repeated measure analysis of variance followed by the Bonferroni method.

Results: Lamotrigine $(4,8$, and $16 \mathrm{mg} / \mathrm{mL})$ significantly decreased the heart rate and contractile force of the isolated guinea pigs' atria $(\mathrm{P}<.001)$. Pretreatment with LTG significantly increased the mean time of onset of the effect of ouabain, the onset of ouabaininduced arrhythmia, and time of ouabain-induced asystole $(\mathrm{P}<.001)$.

Conclusion: LTG reduces the heart rate and contractile force, and also inhibit ouabain induced-arrhythmia of the isolated atria of guinea pigs.
\end{abstract}

Keywords: Lamotrigine, Arrhythmia, Sudden Unexpected Death in Epilepsy, Cardiac Effect, Cardiac Arrest

Conflicts of Interest: None declared

Funding: None

\section{*This work has been published under CC BY-NC-SA 1.0 license. \\ Copyright $\odot$ Iran University of Medical Sciences}

Cite this article as: Mirsalehi M, Malihi G, Bahrami E, Akbarnejad Z, Ahmadi S. Effect of Lamotrigine on Ouabain-Induced Arrhythmia in Isolated Atria of Guinea Pigs. Med J Islam Repub Iran. 2021 (20 Oct);35:138. https://doi.org/10.47176/mjiri.35.138

\section{Introduction}

\section{Lamotrigine}

(LTG),

(3,5-diamino-6-(2,3dichlorophenyl)-1,2,4-triazine) is an antiepileptic drug, (AED) which is effective against partial and generalized seizures and is used in both elderly adults and children (1). It is also indicated in some psychiatric disorders, such as bipolar disorder (2). LTG blocks voltage-gated sodium channels (VGSC) $(3,4)$, and $\mathrm{N}$ - and P/Q-type calcium channels on presynaptic nerve terminals (5). The sodium

Corresponding author: Dr Sayedali Ahmadi,Ahmadi.as@iums.ac.ir

1. ENT and Head \& Neck Research Center and Department, Hazrat Rasoul Hospital, The Five Senses Health institute, Iran University of Medical Sciences, Tehran, Iran

2. Fargol Research Group, Ballwin, Missouri, USA

3. Department of Neurosurgery, Hazrat Rasoul Hospital, Iran University of Medical Sciences, Tehran, Iran channel blocker drugs affect neurons as well as the cardiac conduction system and myocardium $(6,7)$. Phenytoin is another antiepileptic drug with an effect like LTG in voltage-dependent sodium channels that have been classified as an antiarrhythmic drug (6). The cardiac effects of LTG has been reported in overdose and toxicity in the literature $(8,9)$. LTG toxicity could induce a prolonged QRS complex in ECG, which is refractory to sodium bicarbonate

$\uparrow$ What is "already known” in this topic:

Many antiepileptic drugs have cardiac effects. This category of drugs can affect arrhythmia and sudden death in epileptic patients. Mechanism of action of lamotrigine in the brain and cardia could have similarities in at least 1 voltage gate $\mathrm{Na}$ channel.

\section{$\rightarrow$ What this article adds:}

The study showed the important effect of lamotrigine on the heart rate and contractile force, and also inhibition of ouabain induced-arrhythmia of the isolated atria of guinea pigs. 
(8).

Ouabain is a cardiac glycoside that can induce triggered pacemaker-induced arrhythmia (10). Ouabain inhibits plasma membrane $\mathrm{Na}+/ \mathrm{K}+$ ATPase and increases intracellular $\mathrm{Na}+$ concentration. The increases in intracellular $\mathrm{Na}+$ concentration cause intracellular $\mathrm{Ca} 2+$ overload because of activation of sarcolemmal $\mathrm{Na}+/ \mathrm{Ca} 2+$ exchange(10). The rise in intracellular $\mathrm{Ca} 2+$ leads to extrasystole and cardiac arrhythmia. Ouabain is widely used to screen and evaluate antiarrhythmic drugs (11-13). In many studies, it has been used to induce arrhythmia and is ideal for animal models to study arrhythmia (14).

Arrhythmia in epilepsy has been described for many years (15). Sudden unexpected death in epilepsy (SUDEP) is the leading cause of epilepsy-related premature mortality (16). Arrhythmia or mutation in sodium channels is known as pathophysiologic mechanisms of SUDEP (1619).

The primary goal of our study is to explain the antiarrhythmic activity of LTG in arrhythmia produced by ouabain in isolated atria of guinea pigs to discuss the mechanism behind the phenomenon.

\section{Methods}

Preparation of the Atria of Guinea Pigs: All the experiments were approved by the ethics institute Committee of the Animal Care of Shahid Beheshti University of Medical Sciences. A total of 21 maleguinea pigs weighing 300 to $500 \mathrm{~g}$ were anesthetized by ether and exsanguinated. The heart was rapidly removed; the atria were dissected from the heart, and suspended in a bath containing $50 \mathrm{~mL}$ oxygenated modified Krebs solution at 36 to $37{ }^{\circ} \mathrm{C}$ and $\mathrm{pH}$ 7.4. The composition of solution was as follows (mM): $\mathrm{NaCl} 118.0, \mathrm{KCl} 4.7, \mathrm{CaCl}_{2} 2.6, \mathrm{MgCl}_{2}$ 1.2, $\mathrm{NaH}_{2} \mathrm{PO}_{4}$ 1.0, $\mathrm{NaHCO}_{3}$ 25.0, glucose 11.1, EDTA 0.004, and ascorbic acid 0.11. After mounting, the preparations were left for 30 minutes for equilibration. The diastolic tension on the atrial preparation was adjusted on $0.5 \mathrm{~g}$.

Treatment of the Atria With Lamotrigine: The plan of the experiment was as follows: Group I: 7 atria were examined after 30 minutes, LTG (Welcome) was added to the bath in doses of $2,4,8$, and $16 \mathrm{mg} / \mathrm{mL}$. Solutions of drugs were prepared where a constant volume of $0.5 \mathrm{~mL}$ for each dose was added to a $50 \mathrm{~mL}$ bathing fluid $(20,21)$. The heart rate and contractile force of spontaneous contractions were measured by the photosensitive transducer on a Beckman RS Dynograph recorder isometrically for each dose and compared with the baseline measurement (dose zero). The duration of spontaneous rhythmicity of guinea pig atrial preparations under the conditions of our experiment was 25 to 35 minutes.

Ouabain-Induced arrhythmia and Pretreatment With Lamotrigine: In group II, a total of 14 atria were exposed to ouabain, and the onset of arrhythmia and asystole were evaluated with and without pretreatment of Lamotrigine: Group IIa: Six atria were treated only with ouabain (Sigma) $(1.2 \mathrm{mg} / \mathrm{mL})$ after 30 minutes. Group IIb: Eight atria were pretreated with $8 \mathrm{mg} / \mathrm{mL}$ LTG for 10 minutes, and then ouabain $(1.2 \mathrm{mg} / \mathrm{mL})$ was added to the bath in the presence of LTG. The onset of effect, arrhythmia, and asystole were measured for each group and compared together.

Statistical Analysis: The SPSS Version 16 ( SPSS Inc) was used for data analysis. The results were summarized with means \pm SD. The statistical comparisons were made by using Student's t test and repeated measure analysis of variance followed by the Bonferroni method. The statistical significance was set at $\mathrm{p}<0.05$.

\section{Results}

Lamotrigine at the concentrations of $2,4,8$, and 16 $\mu \mathrm{g} / \mathrm{mL}$ significantly reduced the contractile force of the isolated guinea pigs' atria $(\mathrm{p}<0.001)($ Table 1$)$.

Figure 1 demonstrates the effect of various doses of lamotrigine on the contractile forces of the atria. Upon elevation of the dose of Lamotrigine, the contractile force of the atria decreased significantly.

Lamotrigine at the concentrations of 4,8 , and $16 \mu \mathrm{g} / \mathrm{mL}$ significantly reduced the heart rate of the isolated guinea pigs' atria (Table $1, \mathrm{p}<0.001$ ). Figure 2 displays the effectiveness of various doses of lamotrigine on the heart rate of the atria (Fig. 3).

There was no statistically significant difference between dose zero and $2 \mu \mathrm{g} / \mathrm{mL}$, but by increasing the dose of the lamotrigine to 4,8 , and $16 \mu \mathrm{g} / \mathrm{mL}$, the heart rate decreased significantly.

Pretreatment with Lamotrigine increased the mean onset of the effect of ouabain from $1.39 \pm 0.32$ minutes to $3.56 \pm 0.68$ minutes $(p<0.001)$. The onset of ouabaininduced arrhythmia rose from $6.14 \pm 0.87$ to $10.59 \pm 1.03$ minutes $(p<0.001)$. The time of ouabain-induced asystole increased from $14.59 \pm 1.60$ minutes to $22.89 \pm 1.63$ minutes $(\mathrm{p}<0.001)$ with pretreatment with Lamotrigine (Figs. 4 and 5).

\begin{tabular}{lcc} 
Table 1. The Contractile Force and Heart Rate of Guinea Pigs' Atria After Exposure to Different Doses of Lamotrigine \\
\hline Dose $(\mu \mathrm{g} / \mathrm{ml})$ & $\begin{array}{c}\text { Contractile force }(\mathrm{g}) \\
\text { Mean (SD) }\end{array}$ & $\begin{array}{c}\text { Heart rate (per minute) } \\
\text { Mean (SD) }\end{array}$ \\
\hline 0 (control) & $11(1)$ & $175(22)$ \\
2 & $9(1)$ & $169(24)$ \\
4 & $7(2)$ & $149(25)$ \\
8 & $5(2)$ & $142(27)$ \\
16 & $4(2)$ & $129(29)$ \\
\hline
\end{tabular}




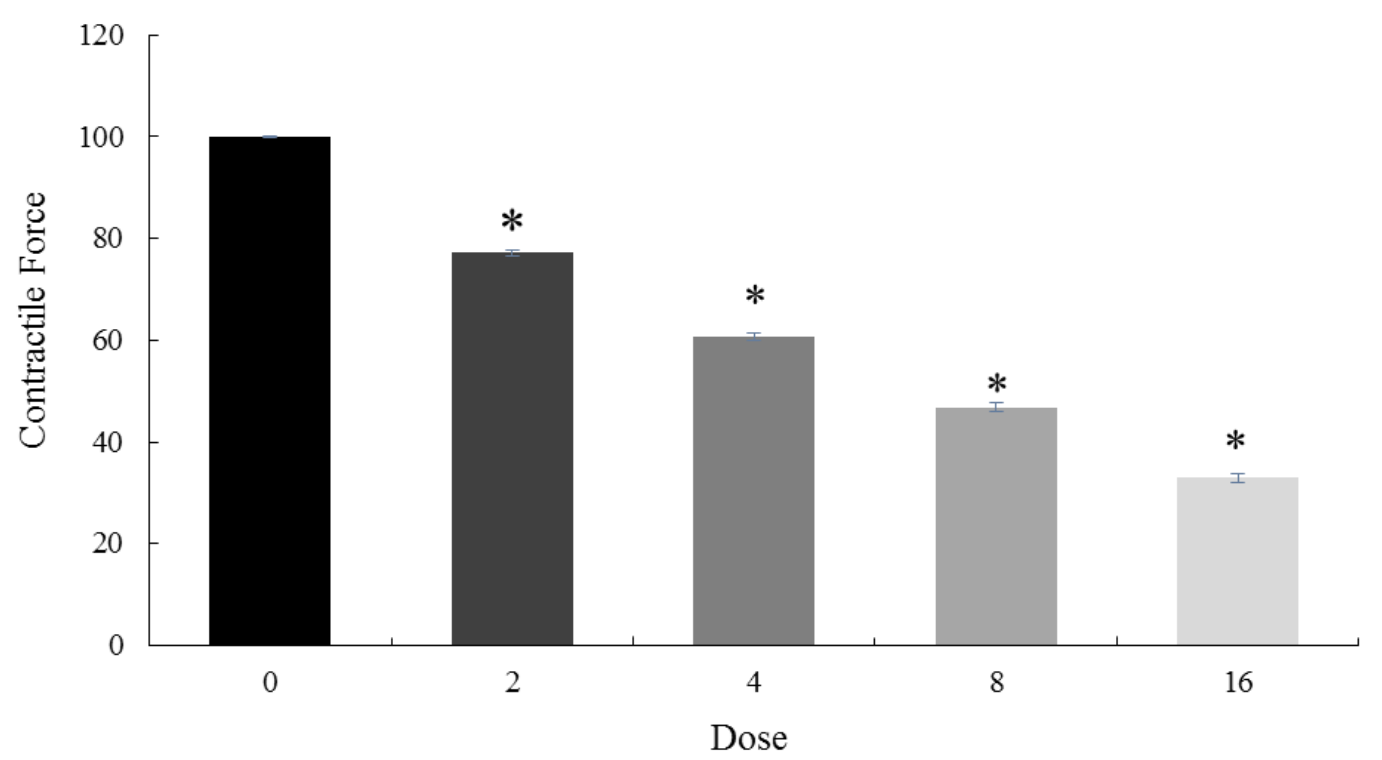

Fig. 1. The effect of different doses of lamotrigine on contractile forces of the guinea pigs' atria. The values are reported in percentile compared with the baseline (dose zero). *: significant difference compared with dose zero.

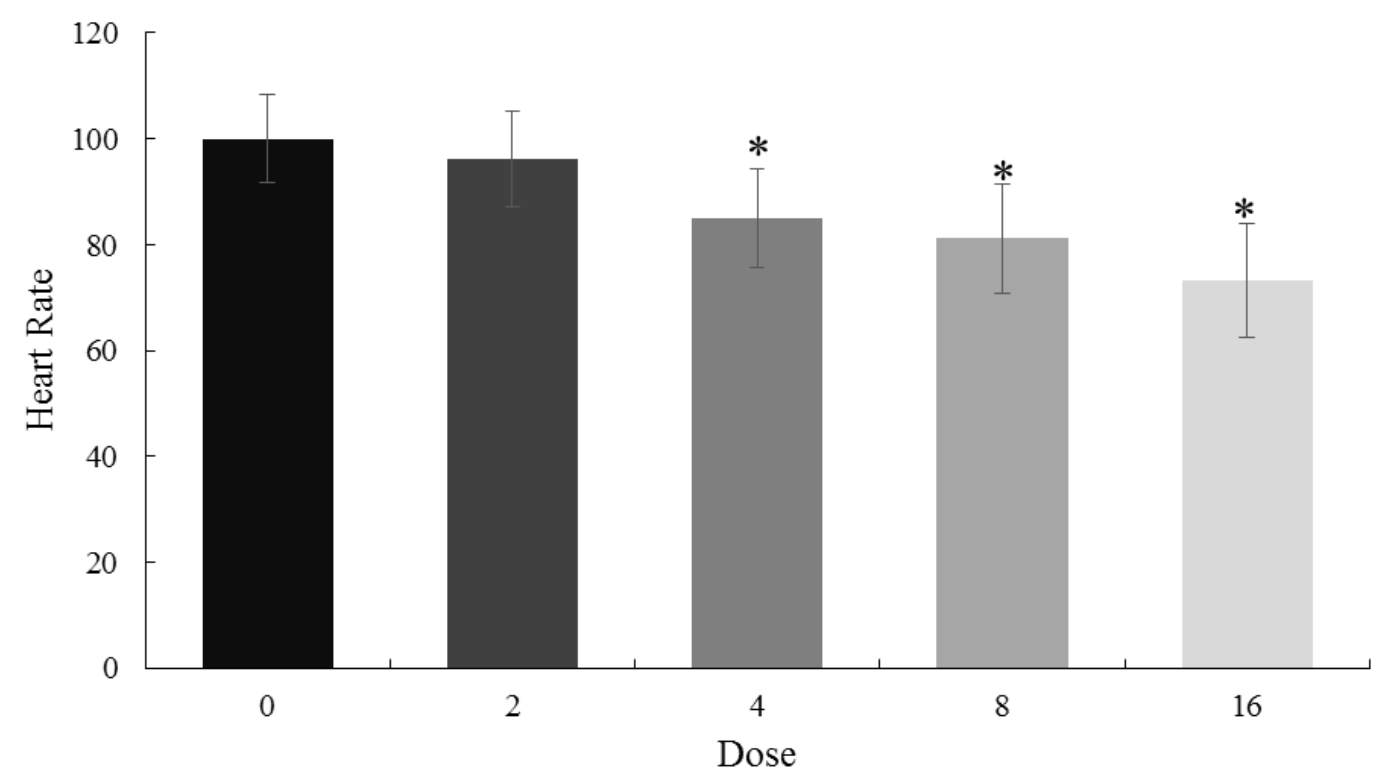

Fig. 2. The effect of different doses of lamotrigine on contractile heart rate of the guinea pigs' atria. The values are reported in percentile compared with baseline (dose zero). *: significant difference compared to dose zero.
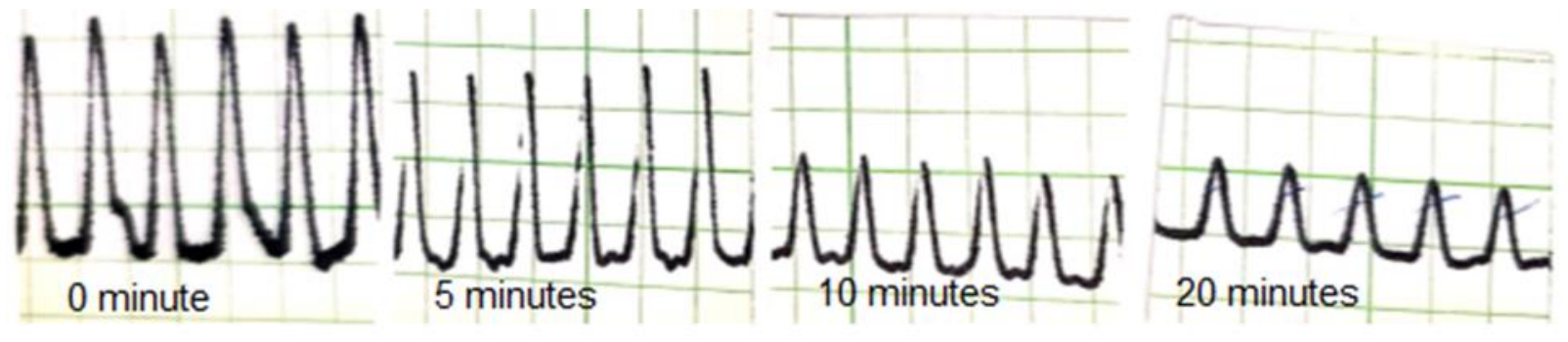

Fig. 3. The effect of LTG $(8 \mu \mathrm{g} / \mathrm{mL})$ on contractile force in isolated guinea-pig atrium

\section{Discussion}

Lamotrigine (Lamictal, LTG) is an antiepileptic drug that is effective in partial and generalized seizures in both the elderly and children $(3,22)$. Further, LTG is indicated

http://mjiri.iums.ac.ir

Med J Islam Repub Iran. 2021 (20 Oct); 35.138. 


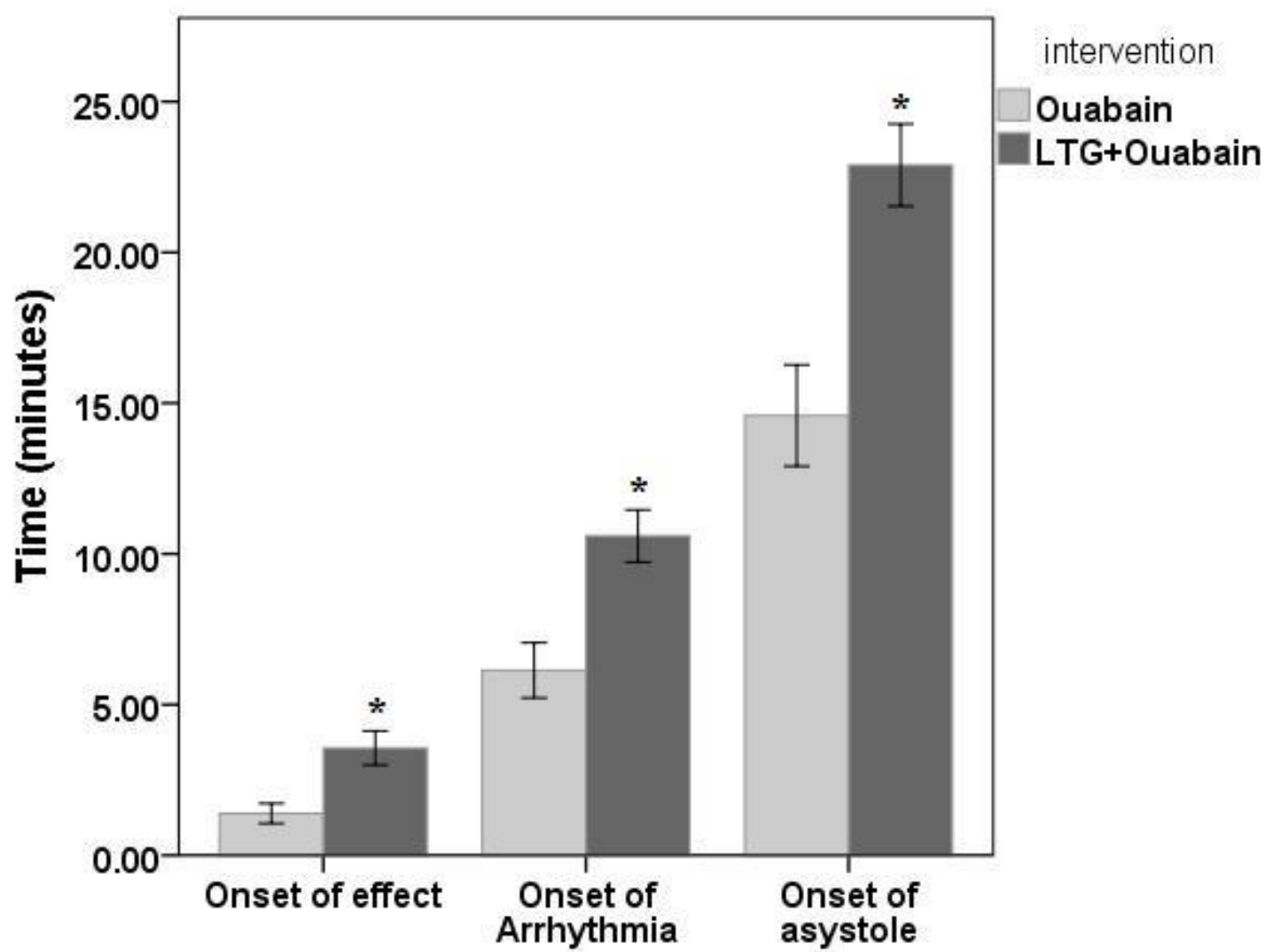

Fig. 4. The effect of pretreatment with lamotrigine on the onsets of effect, arrhythmia, and asystole due to ouabain. LTG, lamotrigine, *: shows $\mathrm{P}<0.05$, the error bars show the $95 \% \mathrm{CI}$.

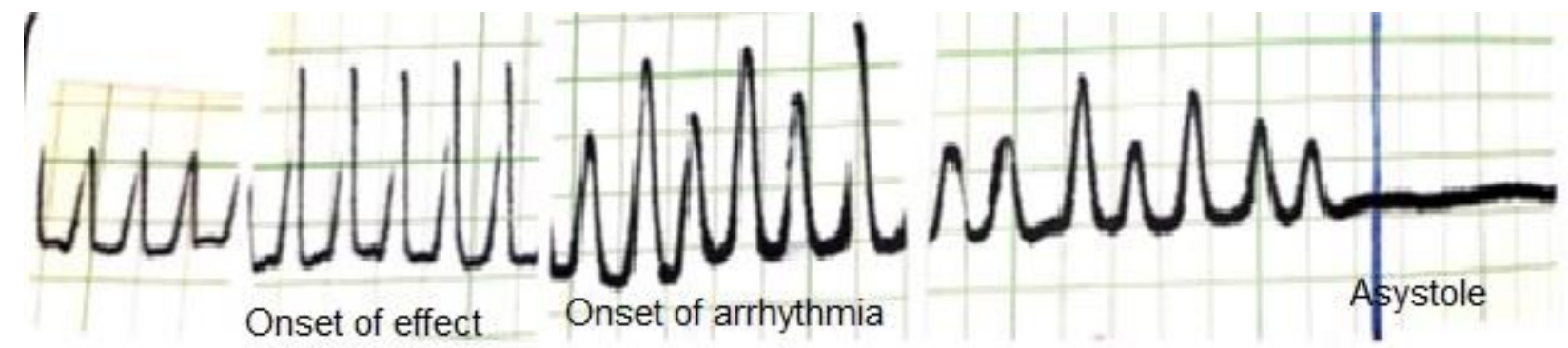

Fig. 5. Arrhythmia and asystole induced by ouabain in the isolated atrium of guinea pigs

as an add-on treatment for drug-resistant focal seizures (23) as well as for migraine and neuropathic pain (24). It is also approved for bipolar prophylaxis in psychology and the treatment of psychiatric diseases, such as acute bipolar depression, treatment-resistant schizophrenia, treatment-resistant obsessive-compulsive disorder, posttraumatic stress disorder, and depersonalization disorder, along with affective dysregulation and behavioral dyscontrol domains of borderline personality disorder (2).

LTG, similar to phenytoin and carbamazepine, modulates the voltage-gated sodium channels $(5,4)$. VGSCs are composed of an $\alpha$-subunit and a $\beta$-subunit. Based on recent studies, 9 different $\alpha$-subunits (Nav1.1-1.9) and 4 different $\beta$-subunits $(\beta 1-\beta 4)$ have been identified in mammals (25). These VGSCs are distributed on different organs, such as the central nervous system, sensory neurons, skeletal muscles, cardiac muscles, sympathetic neu- rons, and Schwann cells (25).

Some other drugs that affect these channels have similar effects on different organs. The cardiac effect of phenytoin (26) and the anti-neuropathic effect of carbamazepine (27) are 2 examples of clinical use of these drugs on VGSCs located in other organs.

Some studies have found the cardiac effect of lamotrigine in the clinic (9). Cardiac conduction delays, wide complex tachycardia, and death have been reported in acute lamotrigine overdose (28).

We evaluated the effect of LTG on isolated guinea pig atria for illustration of the cardiac effect of this drug. In our study, there was no statistically significant difference between dose zero (baseline) and $2 \mu \mathrm{g} / \mathrm{mL}$, but by increasing the dose of the lamotrigine to 4,8 , and $16 \mu \mathrm{g} / \mathrm{mL}$, the heart rate decreased significantly $(\mathrm{p}<0.001)$.

SUDEP is one of the reasons for mortality in adults and 
children $(16,18,19,29)$. Although many general risk factors for SUDEP have been identified, VGSCs genetic variations are known as a cause of SUDEP, which variations can induce a seizure in the brain and arrhythmia in the heart $(19,30)$. There are many studies to evaluate the effect of LTG on SUDEP in the clinic, but they could not find a statistically significant difference in the relationship between SUDEP and LTG use (31).

Ouabain is used to develop stable and ideal animal models for arrhythmias and widely used to screen and evaluate antiarrhythmic drugs (14). Ouabain binds and inhibits the plasma membrane $\mathrm{Na}+\mathrm{K}+-\mathrm{ATPase}$ (sodium pump) and increases intracellular $\mathrm{Ca} 2+$ concentration, leading to extrasystoles and ventricular arrhythmias (11, 12). High doses of ouabain often trigger activity-induced cardiac arrhythmias (10). We used ouabain to induce arrhythmia in isolated guinea pig atria. The effect of LTG on ouabain-induced arrhythmia was evaluated by pretreatment of the atria with LTG and then adding the ouabain to the isolated atria. The results were compared with the atria with exposure to ouabain only with the same dose. Pretreatment of isolated atria of the guinea-pigs with LTG significantly increased the time of effect, the onset of arrhythmia, and the time of asystole due to ouabain $(\mathrm{p}<0.001)$. LTG might delay the ouabain-induced arrhythmia by inhibiting $\mathrm{Na}+$ channels. Our results suggest that LTG may have also antiarrhythmic as well as proarrhythmic properties.

\section{Conclusion}

LTG as an antiepileptic drug can induce a negative effect on the heart rate and the cardiac contractile force and can also can inhibit ouabain-induced arrhythmia on the isolated atria of guinea pigs.

\section{Acknowledgment}

The authors would like to acknowledge Somaye Akbari for editing the manuscript.

\section{Conflict of Interests}

The authors declare that they have no competing interests.

\section{References}

1. Aldenkamp AP, Baker G. A Systematic Review of the Effects of Lamotrigine on Cognitive Function and Quality of Life. Epilepsy Behav. 2001;2(2):85-91.

2. Naguy A, Al-Enezi N. Lamotrigine Uses in Psychiatric Practice. Am J Ther. 2019;26(1):e96-e102.

3. Tikhonov DB, Zhorov BS. Mechanism of sodium channel block by local anesthetics, antiarrhythmics, and anticonvulsants. J Gen Physiol. 2019;149(4):465-481.

4. Nakatani Y, Masuko H, Amano T. The effect of lamotrigine on Nav1.4 voltage-gated sodium channels. J Pharmacol Sci. 2013;123(2):203-206.

5. Sills G, Rogawski MA. Mechanisms of action of currently used antiseizure drugs. Neuropharmacology. 2019;168:107966.

6. Kennebäck G, Ericson M, Tomson T, Bergfeldt L. Changes in arrhythmia profile and heart rate variability during abrupt withdrawal of antiepileptic drugs. Implications for sudden death," Seizure. 1997;6(5):369-75.

7. Ishizue N, Niwano S, Saito M, Fukaya H, Nakamura H, Igarashi T, et al. Polytherapy with sodium channel-blocking antiepileptic drugs is associated with arrhythmogenic ST-T abnormality in patients with epilepsy. Seizure. 2016;40:81-87.

8. Chavez P, Casso Dominguez A, Herzog E. Evolving Electrocardiographic Changes in Lamotrigine Overdose: A Case Report and Literature Review. Cardiovasc Toxicol. 2015;15(4):394398.

9. Dream A, Holmgren H, Merrill R, Erin L. Refractory Ventricular Fibrillation in Patient Taking Lamictal. Am $\mathrm{J}$ Emerg Med. 2018;36(7):1324.e1-1324.e2e.

10. Watano T, Harada Y, Harada K, Nishimura N. Effect of $\mathrm{Na}+$ / Ca 2 + exchange inhibitor, KB-R7943 on ouabain-induced arrhythmias in guinea-pigs. Br J Pharmacol. 1999;649:1846-1850.

11. Nasher M, Shpolansky U, Viola N, Dvela M, Buzaglo N, Cohen Ben-Ami H, et al. Ouabain attenuates cardiotoxicity induced by other cardiac steroids. Br J Pharmacol. 2010;160(2):346-354.

12. Lingrel JB. The Physiological Significance of the Cardiotonic Steroid/Ouabain-Binding Site of the Na,K-ATPase. Annu Rev Physiol. 2010;72(1):395-412.

13. Sapia L, Palomeque J, Mattiazzi A, Petroff, MV. Na+/K+-ATPase inhibition by ouabain induces CaMKII-dependent apoptosis in adult rat cardiac myocytes. J Mol Cell Cardiol. 2010;49(3):459-468.

14. Zhou Y, Wu Y, Deng L, Chen L, Zhao D, Lv L, et al.. The alkaloid matrine of the root of Sophora flavescens prevents arrhythmogenic effect of ouabain. Phytomedicine. 2014;21(7):931-935.

15. Sánchez-Borque P, González-Giráldez B, Benezet-Mazuecos J, Miracle A, Crosa J, Rubio JM. Ictal asystole: A condition between neurology and cardiology. Int J Cardiol. 2019;278:104-107.

16. Manolis TA, Manolis AA, Melita H, Manolis AS. Sudden unexpected death in epilepsy: The neuro-cardio-respiratory connection. Seizure. 2018;64:65-73.

17. Opeskin K, Berkovic SF. Risk factors for sudden unexpected death in epilepsy: a controlled prospective study based on coroners cases. Seizure. 2003;1311(2):456-464.

18. Coll M, Oliva A, Grassi S, Brugada R, Campuzano O. Update on the genetic basis of sudden unexpected death in epilepsy. Int J Mol Sci. 2019;20(8): 1979 .

19. Thom M, Boldrini M, Bundock E, Sheppard MN, Devinsky O. Review: the past, present and future challenges in epilepsy related and sudden deaths and biobanking. Neuropathol Appl Neurobiol. 2019;44(1):32-55.

20. Pousti A, Malihi G, Naghibi B. Effect of citalopram on ouabaininduced arrhythmia in isolated guinea-pig atria. Hum Psychopharmacol. 2003;18(2):121-124.

21. Pousti A, Deemyad T, Brumand K, Bakhtiarian A. The effect of fluvoxamine on ouabain-induced arrhythmia in isolated guinea-pig atria. Pharmacol Res. 2005;52(2):151-153.

22. Abou-Khalil BW, Bassel D, Abou-Khalil W, Abou-Khalil D. Update about Antiepileptic drugs -2019. Contin (Minneap Minn). 2019;25:508-536.

23. Panebianco M, Bresnahan R, Ramaratnam S, Marson AG. Lamotrigine add-on therapy for drug-resistant focal epilepsy. Cochrane database Syst Rev. 2020;3:CD001909.

24. Werz MA. Pharmacotherapeutics of epilepsy: Use of lamotrigine and expectations for lamotrigine extended release. Ther Clin Risk Manag. 2008;4(5):1035-1046.

25. Ekberg J, Adams DJ. Neuronal voltage-gated sodium channel subtypes: Key roles in inflammatory and neuropathic pain. Int $\mathrm{J}$ Biochem Cell Biol. 2006;38(12):2005-2010.

26. Guldiken B, Rémi J, Noachtar S. Cardiovascular adverse effects of phenytoin. J Neurol. 2016;263(5):861-870.

27. Kim KH, Seo HJ, Abdi S, Huh B. All about pain pharmacology: what pain physicians should know. Korean J Pain. 2020;33(2):108120 .

28. Alyahy B, Friesen M, Nauche B, Laliberté M. Acute lamotrigine overdose: a systematic review of published adult and pediatric cases. Clin Toxicol. 2018;56(2):81-89.

29. Glasscock E. Genomic biomarkers of SUDEP in brain and heart. Epilepsy Behav. 2018;38(1):172-179.

30. Goldman AM, Behr ER, Semsarian C, Bagnall RD, Sisodiya S, Cooper PN. Sudden unexpected death in epilepsy genetics: Molecular diagnostics and prevention. Epilepsia. 2016;57:17-25.

31. T. Tomson, Hirsch LJ, Friedman D, Bester N, Hammer A, Irizarry $M$, et al. Sudden unexpected death in epilepsy in lamotrigine randomized-controlled trials. Epilepsia 2013;54(1):135-140. 